\title{
"The bike breaks down. What are they going to do?" Actor-networks and the Bicycles for Development movement
}

\author{
Mitchell McSweeney, York University, Canada \\ Brad Millington, University of Bath, UK \\ Lyndsay Hayhurst, York University, Canada \\ Brian Wilson, University of British Columbia, Canada \\ Madison Ardizzi, University of British Columbia, Canada \\ Janet Otte, Mavuno Ministries, Uganda
}

\begin{abstract}
This manuscript reports on an empirical study of 'Bicycles for Development' (BFD) - a nascent movement whereby used bicycles are collected (often in the global North) and distributed in development contexts (often in the global South) with the aim of achieving a range of positive social outcomes (e.g., access to education). Drawing from interviews $(n=32)$ with participants from 19 BFD organizations, and informed by Actor-Network Theory (ANT), the analysis presented herein specifically highlights three key factors that facilitate and/or hinder BFD work: 1) government regulations that potentially stem or ease the flow of bicycles into development contexts; 2) the bicycle's material constitution, and specifically its sturdiness (or lack thereof); and 3 ) environmental conditions that impact how bicycles are made, distributed, and used. A key theme that cuts across these findings is the potential for non-humans to cause 'frictions' that potentially disrupt, divert, but also help in realizing the programs of action of BFD organizations. We consider the relevance of these findings for both the BFD movement in particular and the wider Sport for Development and Peace (SDP) movement in general. Based on study findings, we argue for ANT as a useful framework for achieving a widened analytical focus and thus for delivering more robust accounts of development contexts under study.
\end{abstract}

\section{Key words}

Bicycles; Sport; Physical culture; Development; New materialism; Mobility

This is the accepted version of the manuscript for International Review for the Sociology of Sport. 


\section{Introduction}

What development roles do bicycles play in disadvantaged communities? How do bicycles enter, move within, and leave these communities? What, if anything, confounds this movement? And what can we learn from bicycles about the role of sport and physical activity in development initiatives in general?

In this paper, we consider these questions through a description and critical assessment of a growing but understudied movement: 'Bicycles for Development' (BFD). The fundamental idea underpinning BFD is that bicycles are uniquely positioned to assist in achieving development goals, conducive as cycling is to both exercise and efficient mobility. In recent years, key actors ranging from the United Nations (UN) to non-governmental organizations (NGOs) to corporations and beyond have deemed the bicycle a conduit for achieving goals such as poverty reduction, health promotion, and youth development and education (Yang and $\mathrm{Wu}, 2015$ ). Bicycles purportedly hold immense potential in the global South and in marginalized communities in the global North in particular. Indeed, while some BFD work is situated exclusively at the local level, it is not uncommon for BFD organizations to solicit bicycle donations in one part of the world (often in the global North) and then distribute bicycles through sales or donations elsewhere (often in the global South).

In this article, we report findings from an empirical study that featured interviews with participants from BFD organizations. The research reported herein was motivated in the first instance by the above-described trend whereby bicycles have been heralded for their transformational potential. Equally, however, we were compelled by two noteworthy gaps in the scholarly literature. 
First, the BFD movement is reflective of the wider Sport for Development and Peace (SDP) movement, whereby sport is used to promote social outcomes such as increased social capital, gender equality, improved health, and conflict resolution. SDP has received substantial attention in the literature, yet there is a recognized need for research that moves beyond traditional sport (e.g., structured sport competitions) and focuses instead on the development role of less formalized physical cultural activities (Coakley and Donnelly, 2009; Sterchele, 2015). Cycling fits this description.

Second, Darnell et al. (2018) recently argued for research that accounts for the true variety of actors involved in SDP networks, noting the tendency to overlook the important contributions of non-humans in particular. Like Darnell et al. (2018), we address this tendency herein by adopting an Actor-Network Theory (ANT) perspective. The potential upside of adopting ANT is that it can lead to more nuanced understandings of how SDP initiatives actually unfold, and thus, in the long term, to better recommendations on how development initiatives might evolve into the future.

The contributions of this analysis pertain to the sociological study of SDP in general and the global bicycle sharing economy in particular. We consider these contributions in the discussion and conclusion section at the end of this article. Before arriving there, we first review relevant substantive literature on sport and development and reflect on the utility of ANT as a theoretical framework. In the methods section, we provide an overview of the study protocol we followed in interviewing participants from BFD organizations. The penultimate section of the manuscript reports on three main findings emerging from this research. These pertain to: 1) government policies described as inhibiting or facilitating the movement of bicycles into development contexts; 2) bicycle composition as a factor in the success or failure of BFD; and 3) environmental conditions 
that impact how bicycles are made, distributed, and used. A key theme that cuts across these findings is the potential for non-humans to cause 'frictions' that disrupt, divert, but in most cases ultimately help produce, BFD work. As noted, we conclude with an analysis of the significance of these results.

\section{Literature Review}

Sport for Development and Peace (SDP) and Bicycles for Development (BFD)

As a practice and wider movement, SDP generally positions sport as a viable tool for development - especially in the global South, but also in underprivileged communities in the global North. SDP has earned backing from influential organizations such as the $\mathrm{UN}$, who position sport as a 'universal language' and thus an optimal means for promoting development (United Nations, 2004). An even greater driving force for SDP, however, is the wide array of NGO practitioner organizations that have emerged in recent years with the aim of using sport for achieving ends such as conflict resolution, health promotion (e.g., HIV prevention), improved education, gender equality, and individual and community empowerment (e.g., see Darnell, 2012; Levermore, 2011; Svensson and Woods, 2017).

In terms of the SDP literature, Schulenkorf, Sherry, and Rowe (2016) recently identified a series of key trends in academic research on sport-themed development initiatives ${ }^{1}$. Among the key findings of their integrative review is that the corpus of SDP research has indeed grown substantially and fairly steadily this millennium. The specific thematic areas covered in this literature include disability, gender, health, livelihoods, peace, social cohesion, and education - of these, the latter two have featured especially prominently in the literature. For example, Sherry's

\footnotetext{
${ }^{1}$ Schulenkorf, Sherry, and Rowe (2016) refer to Sport for Development (SFD) in their analysis. Herein, we consider SFD and SDP to be synonymous.
} 
(2010) analysis of the Street Socceroos - an Australia-based Homeless World Cup (HWC) football team - concludes with the view that participation in the HWC is especially impactful for marginalized or socially excluded groups: "Team members benefited from this participation with both the intrinsic benefits of developing a sense of belonging and pride, and generation of economic and cultural capital, through more stable housing, employment, and study" (p. 68). Welty Peachey, Cohen, Borland, and Lyras (2013) come to the related conclusion that volunteers in street soccer initiatives themselves see benefits in terms of social capital. With this in mind, it is perhaps unsurprising that, in Schulenkorf, Sherry, and Rowe's (2016) analysis, positive youth development and social capital theory were found to be the two main theoretical frameworks used in SDP research.

Yet SDP initiatives have also earned significant criticism in the literature - for instance, "regarding the dominance of international implementers from high-income countries conducting work in low- and middle-income countries" (Schulenkorf, Sherry \& Rowe, 2016, p. 34; also see Levermore, 2009; Lindsey and Grattan, 2012). Schulenkorf, Sherry, and Rowe (2016) note accusations in this regard of neo-colonialist tendencies in program implementation. Hartmann and Kwauk (2014), for example, argue that the 'dominant vision' of sport for development is flawed in the common elision of structural transformation as a key consideration; the focus tends to lie with "sport's ability to resocialize and recalibrate individual youth and young people" (p. 291, also see, e.g., Coalter, 2013; Author, 2012). By contrast, more critical interventionist approaches are geared towards (for example) employing educational initiatives to address extant forms of social injustice. Their focus lies beyond individual remediation.

Thus, there is a paradigmatic tension at play in the literature. As Author (2018) argues, researchers adopting positive youth development and social capital as theoretical frameworks are 
often driven towards solutions to development inequalities (i.e., in an instrumentalist sense). By contrast, other theoretical frameworks or concepts, such as political economy, governmentality, and feminism, consider, more critically, "how sport aligns with or diverges from (or even resists) the histories and structures of inequality" (p. 138). Darnell et al. (2018) make a similar point, noting that a critique of instrumentalist SDP research is its failure to "illuminate the ideologies, politics or funding structures that underpin [SDP] programs, particularly on a global scale" (p. 90, also see Author, 2011). Conversely, more critical approaches to SDP research are arguably flawed in their tendency to begin from and ultimately arrive at an ideological position - namely, that sport reaffirms historical and contemporary power structures. We revisit this point in discussing ActorNetwork Theory below.

As said at the outset, the Bicycles for Development (BFD) movement and its attendant politics and practices are largely absent from the literature. A key exception to this is Furness's (2010) account of community bike projects and bicycle aid. Furness (2010) focuses mainly on the United States, where, dating roughly to the 1970s, community bicycle organizations have operated by collecting used and/or donated bicycles, facilitating access to tools, and running initiatives where (for example) young people receive bicycles in exchange for their work in bicycle repair. Such organizations sometimes have a global outlook as well. Furness (2010) gives credit to the organization Bikes Not Bombs and their work in donating used bicycles in Nicaragua beginning in the 1980s as an important early case of overseas, bicycle-based aid. Village Bicycle Project (VBP), meanwhile, is an example of an organization - in this case founded in Ghana - that does the local work of distributing bicycles donated by organizations situated in the global North.

Importantly, Furness (2010) is attuned to the politics of development work of this kind. This is true in one sense in that a social justice mandate - e.g., comprising a critique of capitalism's 
wastefulness and environmental degradation - is commonplace in the bicycle-based organizations featured in his analysis. It is true as well when it comes to the politics of inclusivity. For instance, Furness (2010) contends that a form of male machismo, founded on factors like mechanical expertise and toughness in cycling, is not uncommon in bike culture.

In another sense still, the politics of development pertain to the decision-making authority of key actors, such as governments and international organizations, in influencing whether cycling is made 'welcome' is certain contexts. A case in point is the World Bank's 2007 report, 'A Decade of Action in Transportation', which, according to Furness (2010), "makes virtually no concrete recommendations for improving non-motorized transportation infrastructure or policies worldwide” (pp. 189-190). Indeed, tensions linger at times between motorized and non-motorized forms of transportation. For example, Pojani and Stead (2015) describe how, in 'developing' cities, the political climate is not always favourable to 'soft modes' of transportation:

Politicians consider walking and cycling as a sign of backwardness and not commensurate with their goals and aspirations. Urban elites distort transport planning in favor of motorized modes, which they are more likely to use themselves. Major international lenders often invest minuscule amounts in nonmotorized improvements. The groups which most heavily rely on non-motorized transport are poorly organized and unable to articulate their needs (p. 7792).

Furness's (2010) account notwithstanding, the role of bicycles in development work merits much greater attention. Though bicycles may at times lose out to motorized transportation, cycling has also been championed recently by the UN "as a tool for development and as a means not just of transportation but also of access to education, health care and sport" (United Nations, n.d.). The UN celebrated the first World Bicycle Day on June $3^{\text {rd }}$, 2018. Corporate donors have supported the BFD cause as well. And, of course, bicycle NGOs continue to distribute bicycles across international lines and in local contexts with positive social change in mind. Altogether, BFD is arguably a movement in the style of the global social movements of recent years: it comprises a 
loose and non-hierarchical affiliation of actors working to achieve better forms of globalization based on values such as democracy, justice, and human rights (see Harvey, Horne \& Safai, 2009). BFD in this sense is not unlike the wider SDP movement, though without the same level of scrutiny from researchers.

\section{Sport and Actor-Network Theory}

As the literature on SDP has flourished, research on sport has, at the same time, helped advance a 'new materialist' turn in the social sciences. In contrast to the preceding discursive turn and its strong social constructionism, new materialism presses beyond human experience through “ontological questions about how 'matter' is thought and constituted through entanglements of human and non-human bodies, affects, objects and cultural practices" (Fullagar, 2017, p. 248; also see Markula, In Press, Author, 2009). Actor-Network Theory (ANT) is among the most prominent new materialist theoretical perspectives.

In Latour's (2005) formulation, ANT represents an attempt at moving beyond a 'sociology of the social', whereby social relations tautologically explain social relations, to a 'sociology of associations', whereby the social is seen as an assemblage of various actors (or 'actants', in Latour's vocabulary) - from discourses to non-human objects to people and beyond. ANT, in other words, suggests, "that society, organizations, agents and machines are all effects generated in patterned networks of diverse (not simply human) materials" (Law, 1992, p. 2). Latour (2005) advocates for a kind of epistemological flattening whereby analytical attention is paid to the points of connection between 'materials' in their different forms. What's more, humans and non-humans alike are understood to have agentic potential - a conceptual move that requires defining agency as "making a difference to some state of affairs" (Latour, 2005, p. 52). Mediators, for Latour (2005), are actants that "transform, translate, distort, and modify the meaning or the elements they 
are supposed to carry" (p. 39). The objects that surround us might seem like passive conduits for human activity ('intermediaries' in Latour's lexicon), but their status as mediators can easily become apparent. An inopportune breakdown of a classroom overhead projector very quickly shows its importance in 'making a difference' to the lecture; the teacher and students are no longer the sole actors on stage. An attempt to fix the projector in turn reveals its many parts, each making a difference in its own right. Those parts perhaps have parts of their own; "How many actants are really there?" (Latour, 1999, p. 183).

Fatimah and Aurora (2016) take up the idea of non-human agency in the development context of an Energy Self-Sufficient Village program in Indonesia. Particularly instructive is Fatimah and Aurora's account of the 'frictions' arising in and through development initiatives. Frictions, they contend, "are a result of (material) resistance posed by humans and nonhumans to the courses of actions attempted according to others' proposals, plans and expectations" (p. 29, see Latour, 1988). The broken bulb or lens in the classroom projector disrupts what Latour (1999) calls the program of action - the series of goals, steps, and intentions - of the teacher. We could apply the term 'friction' here to capture the teacher's newfound challenge and discomfort. Fatimah and Aurora's (2016) own research reveals various ways by which frictions can arise in development contexts. For example, they describe how the material texture of Calophyllum (a tropical plant) fruits changed over time as they moved between different weighing scales, causing disagreement between the pickers and Calophyllum buyers. Tsing (2005) likewise uses the term 'friction' to describe impediments to globalization, though she also emphasizes that frictions can be productive as much as constraining - a point we revisit in detail below.

Darnell et al. (2018) see value in ANT in its ability to account for the intricacies of SDP, thanks to a partial focus on the role played by non-humans in SDP programming. And while Latour 
has been criticized for obscuring power dynamics (e.g., see Harding, 2008; Watson, 2011), Darnell et al. (2018) make the case that ANT can help explain power in development contexts without begging the question. For example, in their own research on SDP organizations in Kingston, Jamaica, Darnell et al. (2018) found that an organization that had traditionally dealt with health and HIV/AIDS prevention turned its focus to sport when this opened up the possibility of obtaining funding and expertise from a UK-based international NGO. In effect, actors such as money, expertise, technical support, "and even the concept of sport's development utility" (p. 95) played a part in holding SDP together - and in revealing power dynamics between the global North and global South (also see Webb and Richelieu, 2016; Author, 2017; Stoddart, 2012).

In this light, ANT presents an intriguing lens for analyzing the bicycle. An ANT perspective on the bicycle - and Bicycles for Development - would be attuned in part to the various networks in which bicycles are imbricated, and to how the programs of action of BFD organizations might be facilitated and/or disrupted by non-humans of various kinds, including bicycles and their constituent parts. This is the form of analysis that we pursue below.

\section{Methods}

The data presented in this paper are drawn from a large-scale research project focused on the BFD movement. The aim of the project, in total, is to explore perspectives and experiences of bicycle users - the ostensible beneficiaries of BFD initiatives - in so-called developing contexts, as well as the intentions and activities of those working for BFD organizations.

The analysis presented herein draws on data from interviews with participants from BFD NGOs. Recruitment involved identifying organizations engaged in bicycle-based development work. This was aided by an initial search exercise aimed at mapping the BFD landscape (i.e., that 
identified where organizations with an online presence are located and where they focus their work). The first author conducted 13 interviews with executives from 9 NGOs based in various places around the globe, including Canada, the US, South Africa, India, the UK, and Sierra Leone. The fifth author undertook interviews with 19 participants from 10 other BFD organizations during fieldwork at the local level in Uganda. The particular focus on the Ugandan context was due to: 1) previous relationships with community-based researchers and gatekeepers; and 2) the fact that numerous BFD organizations operate therein. In total, 32 interviews were conducted over Skype $(n=10)$, by phone $(n=3)$, or in-person $(n=19)$. Interviews ranged from 15 minutes to 2.5 hours in length. A translator assisted when necessary. Interview questions focused on a range of topics, including: 'origin stories' behind BFD organizations; organizational goals; relationships between BFD NGOs; barriers to development work (e.g., around transporting bicycles to development contexts); portrayals of the bicycle sharing economy in media; and the successes and challenges of the BFD movement in general. A key aim in interviews was to elicit insight into the range of actors influencing development work, as per an ANT perspective. This is not perfectly in line with Latour's methodological prescriptions for tracing associations through ethnographic fieldwork (see especially Latour, 2005), but it is nonetheless effective as a step in rendering actors of various kinds 'visible' as part of BFD networks.

The context for this research and the participants involved in the study require further description. Many of the participants are from BFD organizations that are embedded in transnational networks - for example, via international partnerships, relationships with funders, and inter-organizational links. As seen in Table 1, these organizations operate in broadly similar ways, though with some noteworthy differences as well. For example, some participants work for organizations that operate as bicycle 'distributors', meaning they ship bicycles to other 
organizations to sell at affordable prices or to donate in local contexts around the world. Other participants work for organizations that operate primarily at the local-level - for example, through bicycle-based micro-financing schemes. Though the organizational practices described in this research are varied, the idea of the bicycle as a catalyst for development is a common refrain.

A team of four researchers undertook data analysis from February-April 2018. Interviews were transcribed into Microsoft Word; documents were subsequently entered into NVivo 11 coding software to allow the research team to work collaboratively. Each team member involved in coding developed an initial coding scheme. Through weekly meetings, a 'master codebook' was then developed and finalized through a process of discussing data and categories together. For this particular analysis, initial open coding led to broad data categories such as 'challenges of bicycle NGOs', 'environment', 'geographical location', 'nation-state policies', 'sustainability', and 'shipping of bicycles'. Subsequent rounds of analysis led to more specific categories, such as 'government transport policies' and 'sustainability of the bicycle'. Given the focus of this paper, and given the above conceptualization of actor-network 'frictions' in particular, the analysis below pertains to the role of non-humans in facilitating or hindering BFD work. Specifically, in the following section, we account for three factors along these lines: 1) government regulations, such as those that impact on bicycle imports; 2) the bicycle itself and its associated mechanical parts; and 3) the environment, including weather conditions and the nature of cycling terrain.

The project received institutional Research Ethics Board approval before the study protocol was implemented. Pseudonyms are used below in cases where participants requested this. 


\section{Findings}

\section{Ease vs. Need: Regulation as a Source of Friction}

Interviews with participants from BFD organizations revealed how government regulation can serve to stymie or facilitate development work. That is to say, participants at times spoke of a process whereby regulatory initiatives - or at least the perception thereof - mediate between government officials and BFD organizations, and potentially disrupt programs of action by impeding development initiatives before they ever get started.

Pedals 4 Progress (P4P) provides a case in point. In 1991, Pedals 4 Progress (P4P) evidently initiated its first formal international bicycle shipment to Ecuador. The founder of P4P had a personal connection with Ecuador as he had lived in a small town in the eastern Amazon during a term in the Peace Corps. From his time there, he noticed that his bicycle-owning neighbor was able to "get things done much quicker" than everyone else (P4P, Interview 1). This was a moment of inspiration: upon returning to the United States in the 1980s, he decided to collect bicycles and send them to the Eastern Ecuadorian town in which he once lived. But the destination soon changed; by his account, “the Ecuadorian consulate wouldn't give me import clearances to get into Ecuador and then I had a whole bunch of bikes and no place to ship them, and I got the opportunity to start shipping them into Nicaragua" (P4P, Interview 1).

Other participating organizations likewise emerged out of the international movement of founding stakeholders - and likewise encountered complications in moving bicycles across borders. The barriers allegedly set up by the Ecuadorian consulate in the case of P4P proved instructive: "I realized very quickly that I needed to be in different countries because the rules of the road could change at any time in any one country. They could change the government and change the import laws, and again, [we] can't get in there anymore" (P4P, Interview 1). P4P now 
delivers bikes in Albania, Cameroon, Guatemala, Kosovo, and Vietnam, and has done so in other destinations in the past as well. An executive from Village Bicycle Project (VBP), a BFD organization that operates primarily in Ghana and Sierra Leone, made a similar point about the Ghanaian context:

But I believe when the new government came into play in Ghana two years ago, they increased the import fees on bicycles and decreased them on cars and car parts - which, like transportation policy in any country, however you're subsidizing and taxing it is going to have a big impact (VBP, Interview 1).

This is reminiscent of Pojani and Stead's (2015) aforementioned point that bicycle access and use in global South contexts can potentially be stymied by local policies that privilege the car. The 'rules of the road', as described by the P4P interviewee, are a source of friction in the global bicycle sharing economy.

Indeed, the 'friction' concept is appropriate in this regard. Ghana was similarly described by a study participant from the organization 88 Bikes as a country that, due to low import and export taxes on bicycles, was accessible in the past (88Bikes, Interview 1). The participant from Village Bicycle Project described how this changed over time:

So, when I was describing the history of the program, I mentioned that Ghana was selected early on because it was fairly easy and fairly cheap to get bikes into the country. Two years ago Ghana raised the import fees on a container of bikes and it really challenges the sustainable model that we have (VBP, Interview 1).

A participant from another BFD organization made a broader point along these same lines: "you know to be frank, and I almost hate admitting it ... but, we end up sort of helping where it's easiest, not necessarily where it's most needed."

The point here is not to disparage government officials for imposing regulations related to imports and transportation; this is a basic function of government. Nor is the point to disparage organizations pursuing paths of lesser resistance in development work. Instead, the point is that, if a bicycle is construed as an object with agency - if it can indeed change lives, as suggested by 
BFD proponents - its capacity to "modify a state of affairs by making a difference" (Latour, 2005: 52 ) is only realized through the absence or 'smoothing' of friction elsewhere in the chains of association that make up BFD work. As said above, Pedals for Progress, having purportedly been thwarted by the Ecuadorian consulate, had bicycles with dormant agency: "a whole bunch of bikes and no place to ship them."

\section{Skinny Tires and Dropped Handlebars: The Bike Itself as a Source of Friction}

Having jumped regulatory hurdles as necessary, BFD organizations must in turn ensure, as best possible, that bicycles are usable in local contexts. From an ANT perspective, achieving a development-related program of action is contingent on the bike's material constitution, as much as it is on other factors.

What 'usable' means in some cases is that bicycles are fit for a diversity of tasks. The organization First African Bicycle Information Organization (FABIO), for example, operates a 'Cycle to School' project that offers affordable bicycles to students and teachers and establishes school-based bicycle clubs. But, bicycles are valued for their general utility as well. The FABIO interviewee imagined a bicycle user who, "puts her garden tools on her bike, goes to the garden, gets food, puts [it] on the bike, comes home and the same bicycle can be used to carry children to school, as opposed to giving money ... to boda bodas [taxis]" (FABIO, Interview 1).

Sturdiness is another key consideration. The need for robust bicycles again complicates the seemingly straightforward relationship between bicycle donation in one context and bicycle provision in another. A participant from Village Bicycle Project spoke to this issue, noting that, while some organizations may be open to whatever bicycles are donated to them, "if we give an old ten-speed bike with skinny tires and dropped handlebars, that has very low value in the bush 
in rural Africa" (VBP, Interview 1). A participant from World Bicycle Relief likewise described how the bicycles they send to development contexts are selected based on parts and style: "Ideally, [bikes have] no suspension, because it requires less maintenance and those bikes are really not available anymore. Mountain bikes, which are really what we ideally try to send, have become so specialized and so unique in terms of different wheel sizes, and brakes, hydraulic brakes, that impacts what we have to send down" (WBR, Interview 1). An interviewee from the organization Bicycles Against Poverty, who distribute bicycles in rural African communities, made the point that sturdiness goes hand-in-hand with use: "I've seen bikes that are 6 months old and they look like they're 5 years old. I've also seen bikes that are 6 months old and they look like we delivered them yesterday. So depending on what the farmers are using them for, and who is using them, [it] can affect how long they last and how they wear" (BAP, Interview 1).

References to dropped handlebars, skinny tires, and other bicycle components betray the bike's ontology as a collective of articulated parts, each with the capacity to reveal its importance by breaking down and disrupting the user's or the BFD organization's intended program of action. "I think it's this attitude in the West sometimes," said a participant from the organization 88Bikes, "our way is the best way and that our stuff is the best stuff." He continued:

You know, the thing is, the quality [in the West] is probably better in many respects, but you ship a bike in that's on a different system than the bikes they have in most bikes in tiny villages, they can't get parts. The bike breaks down. What are they going to do? (Interview 1).

Indeed, the challenge of bicycle repair was a common theme. A participant from World Bicycle Relief noted how, in BFD work, "you find that people are spending a lot of money on repairs and the bicycles are not functioning, which kind of defeats the purpose of having them" (WBR, Interview 1). An interviewee from the organization Amuru made a similar point: "[another 
challenge] is that we have some other tools within the workshop that are expensive and they are not within Uganda. Sometimes, you look for them in vain" (Amuru, Interview 3).

In all, sources of friction abound. The bicycle is imported and distributed to make a difference to some state of affairs. Faulty brakes, a flat tire, poor suspension, or some other mechanical problem reveals the chains of association that (ideally) keep the bike running smoothly. Local repair people and tools - sometimes specialist tools - are brought into the mix. To cite Latour (2005), how many actants are really there?

The manner of coping with this on the part of BFD organizations is, in some instances, to build local capacity for bicycle repair. As explained on World Bicycle Relief's website, the organization's signature 'Buffalo Bicycle' (discussed in further detail below) is made with simplicity in maintenance in mind:

The Buffalo Bicycle is deliberately compatible with locally available spare parts, requiring only basic tools for maintenance and repair. WBR operates a Field Mechanic Training Program to help keep the bicycles rolling, using a universal training manual that instructs with pictures and diagrams rather than words. To date, over 1,000 field mechanics have been trained, offering riders access to local maintenance (World Bicycle Relief, 2019).

Village Bicycle Project is another exemplar. The organization strives to strengthen bicycle culture and in turn empower communities, and aims to include women and girls in their programming as a way of redressing gender inequalities (see Village Bicycle Project, 2016). To the point at hand, Village Bicycle Project also provides maintenance workshops for new owners and offers training to village bike mechanics. If the bike is inherently frangible, programming of this kind is designed as a bulwark against this. 


\section{Droughts are Indiscriminate: The Environment as a Source of Friction}

The environment presents a third non-human source of friction. The successful use of bicycles is in part contingent on the physical context in question. This third finding aligns closely with the finding above on bicycle composition.

A participant from World Bicycle Relief made this point as it pertains to BFD organizations in general. In some contexts, they noted, it can be taken-for-granted that turning a faucet will have its intended effect. Development work at times presents less certainty:

And so I think as an international NGO, and working with implementing partners in developing countries, that can be unstable in various ways, just that basic implementation can be a barrier. One day your program's detailed implementation plan can be on track and the next day there's a flood that washes out the bridge that gives us the access to the community that we're working in. And so I don't want to embellish the picture there but I think that there's that general barrier in the various countries that we're working in because we are working in very difficult conditions and communities (WBR, Interview $1)$.

More often, however, the point made by interviewees in this regard was that environmental conditions posed challenges to bicycle use for BFD participants.

Weather is one key consideration. Bicycles Against Poverty (BAP) operates via a financing model whereby participants in the program receive individual loans to fund bicycle payments, and subsequently make loan repayments through village savings groups. Evidently, this can potentially be unsettled by forces beyond the organization's or loan recipient's control:

The biggest challenge we faced at the beginning, or mid-last year ... was that there was a really significant drought in this area. And you know droughts are indiscriminate; they affected all of our farmers ... Either their primary income source or their sole income source was gone (BAP, Interview 1).

Rainy season was likewise described as a challenging time by a participant from Union of Hope:

"Rainy season, [farmers] can suffer... and on your bicycle you are coming to work when it's rainy.

And when they are getting back home, it is worse when they are getting back home. You can be bitten by the rain seriously because the bicycle is just open." (UOH, Interview 3 ). 
Cycling terrain is a consideration along these lines as well. World Bicycle Relief's aforementioned Buffalo Bicycles evoke stout endurance in their very name. Buffalo Bicycle is a for-profit subsidiary of World Bicycle Relief, with profits going towards philanthropic programming and cycling infrastructure. The zoomorphic Buffalo Bicycle is said in promotional materials to be "built for big loads on tough roads in africa [sic]" (World Bicycle Relief, 2016). A participant from World Bicycle Relief made this same point:

There has been a lot of work that's gone into the design of our bicycle to create and design something that is appropriate for the rural conditions, particularly in Africa and other developing countries. We have seen over the past year that there have been limitations and look-alike bicycles that are not of the same body. So that's not a barrier because we want people to have bicycles. But the idea of developing the Buffalo Bicycle was making sure that quality bicycle that meets people's needs - for example, it needs to carry heavy loads, needs to travel long distances (WBR, Interview 1).

Thus, the need for a sturdy bicycle, as described in Finding 2, arises in part from the rough terrain on which the bicycle is used, or at least on which it might be used. A similar point was made by a participant from the organization Amuru:

Translator: So he's [interviewee] also saying that he also faces a big challenge because his bike repairing is very costly. That even when he manages to get the money to repair, the spares from here are not as durable as the ones that come with the bike. Then he gave me an example of the tire. If you just buy a tire from here, even if he says if you're riding it on the road that is not smooth with it, some small grasses, even the grasses can pierce it, can puncture it. Then if, if it is punctured, you don't have to roll it, you have to carry it on your shoulder (Amuru, Interview 2).

A participant from 88 Bikes raised this issue as well, and in a way that resonates with the point from Finding 1 that ease of operation is a key consideration in BFD work: "One of the stipulations of our work [is], we want to go to places where bikes are an easy fit, we don't want to give bikes to places where it's not going to make sense" (88Bikes, Interview 1). 'Intense', rugged and mountainous terrain was described as unworkable in particular.

With some exceptions, such as Stoddart's (2012) account of how snowfall impacts on perceptions and experiences of skiing, the physical contexts of physical culture are often 
overlooked in academic accounts (also see Author, 2017, 2016; Weedon, 2015). In this case, contextual factors ranging from flooding to grass - that is, from obviously-dynamic forces to seemingly inactive ones - can stymie either BFD organizations, participant bike users, or both. When terrain is avoided because it is 'intense', it is a friction (in the Actor-Network Theory sense) that literally pertains to friction: it arises when the rubber hits the road.

\section{Discussion and Conclusion}

For Tsing (2005), the metaphor of friction counters the vision of unimpeded 'flows' that characterized optimistic assessments of the emerging global era in the 1990s. Frictions are stymying - for example, when borders impede migration. But they are also productive: "A wheel turns because of its encounter with the surface of the road; spinning in the air it goes nowhere" (p. 5). Tsing's (2005) particular focus lies with frictions that emerge when universal ideals (e.g., environmental protection or social justice) are encountered and reckoned with 'on the ground' (e.g., the social justice concerns immanent to specific contexts). This in turn gives rise to new articulations of culture and power. Frictions are about "contingencies, gaps, and slippages" that manifest in the particular and that, in turn, potentially reformulate the universal (Tsing, 2005: 211).

BFD trades on a universal notion of bicycle access and use as both empowering and instrumental towards various ends: entrepreneurialism, improved health, education, and social justice among them. The above findings pertain to particular frictions that emerge in the pursuit of lofty goals of this kind - and, moreover, as non-humans come together with people to help shape some state of affairs. The bicycle is a non-human object caught up in various chains of association. Its movement across national borders is subject to governance structures facilitating or inhibiting bicycle distribution. Government regulation (or the perception of regulation) dissuades or 
encourages development initiatives; BFD organizations go where they can 'get in'. The bicycle's movement within local contexts is affected by its own composition - its sturdiness (or lack thereof) - and the interplay of the bicycle and its wider environment. Like government policy, local conditions have consequences. 'Intense' terrain might be deemed too much of an impediment to development work, or it might steer innovation towards a stouter bicycle. When the bicycle breaks down - perhaps because, quite literally, of too much friction - it is revealed to house its own network of component parts. The network widens as specialist people and tools are brought in to remedy the situation, and/or as BFD organizations create bicycle maintenance programs to build local capacity. Whether and the extent to which these local frictions re-orient the universal goals of the BFD movement remains to be seen. What is apparent is that they complicate the aspirational vision of BFD writ large.

Thus, the main implication of this analysis is that, while frictions encumber the BFD process, they also re-direct it in productive fashion. Moreover, and in keeping with Tsing's (2005) account, questions of power arise as BFD is (re)imagined. As a case in point, recall the abovedescribed view that the attitude in the West sometimes is that "our way" is best: "but you ship a bike in that's on a different system than the bikes they have in most bikes in tiny villages, they can't get parts. The bike breaks down, what are they going to do?" (88Bikes, Interview 1). This is a common refrain: development initiatives are often critiqued for being disconnected from local needs and capacities (e.g., see Darnell, 2012; Hartmann \& Kwauk, 2014). In this case, however, the critique is suggestive of human and non-human agency alike: someone is shipping, but something is breaking. The present and looming impacts of climate change on development initiatives present another case in point. Uganda, for example, where many organizations referred to in this research operate, has been subject to intense flooding and drought conditions in recent 
years (UN Environment, 2018). Given the view of study participants that BFD work is especially difficult under such circumstances, extreme weather risks exacerbating the uneven distribution of bicycles and the benefits of cycling.

More broadly, given how BFD mirrors the wider SDP movement, a further implication here is that research on SDP in general might be well-served by a widened observational and analytical focus - one aimed at "the array of forces and actors (human and non) that influence the organization and deployment of SDP" (Darnell et al., 2018: 96). Our point here follows from Latour's claim (2005) that ANT is not based on the view that objects act instead of people:

[ANT] simply says that no science of the social can even begin if the question of who and what participates in the action is not first of all thoroughly explored, even if it might mean letting elements in which, for lack of a better term, we would call non-humans (p. 72, emphasis in original).

To understand BFD, it seems vital to 'let in' a diverse collective: practitioner organizations, global NGOs like the UN, conceptual terms such as empowerment, government policy, BFD staff working 'on the ground', bicycle recipients such as farmers in micro-financing schemes, bicycles and their component parts, maintenance workers with specialist tools, drought conditions, rogue blades of grass, and surely many others not accounted for here. It stands to reason that a similarly complex picture arises with SDP initiatives of other kinds. Yet non-humans have, to a great extent, been left out of the frame, despite their agentic and disruptive potential.

This analysis is intended as one step in widening the frame. The aim has been to assess an unstructured physical cultural practice that is now prominent in the development sector - and specifically to consider the role of non-humans therein. We make no pretense in this analysis of having exhaustively mapped the chains of association in which bicycles are implicated. A strength of this study is the empirical data elicited through the research process. But we recognize that other approaches, such as ethnography, might have elicited further depth of insight. For example, above 
we described the view that developing local capacity for bicycle repair can help in successfully integrating bicycles into development contexts. Furness's (2010) observation that, in the United States at least, the role of bike mechanic is often a gendered one - set as it is in bike cultures that might be characterized by machismo - raises questions about the politics of inclusivity as bicycles move across borders. Compared to Furness's account, maintenance work in BFD might be more or less inclusive along gender lines, though it is notable in this regard that BFD organizations sometimes explicitly set out to address gender inequalities. Questions linger as well regarding whether BFD programs fully align with the needs and interests of the communities in which they operate, or whether a development agenda is imposed 'from above' - as per a common critique in the SDP literature. Future research might also 'backtrack' from the point at which bicycles are circulated in developing contexts by examining chains of association that bring bicycles of certain kinds to market in the first place and the practices and politics of bicycle donation.

In all, neither SDP nor BFD show signs of slowing down. Whether a bicycle, a soccer ball, the composition of the air, the weather, plant or animal life, or something else, an ANT perspective is potentially fruitful in remaining open to the possibility that non-humans can inflect, as much as facilitate, intended programs of action. 


\section{References}

Coakley J and Donnelly P (2009) Sports in Society: Issues and Controversies (2nd ed.). Toronto, Canada: McGraw-Hill Ryerson.

Coalter F (2013) Sport for Development: What Game are we Playing? London: Routledge.

Darnell SC (2012) Sport for Development and Peace: A Critical Sociology. London: Bloomsbury.

Darnell SC, Giulianotti R, Howe PD and Collison H (2018) Re-assembling sport for development and peace through actor network theory: Insights from Kingston, Jamaica. Sociology of Sport Journal 35: 89-97.

Fatimah YA and Arora S (2016) Nonhumans in the practice of development: Material agency and friction in a small-scale energy program in Indonesia. Geoforum 70: 25-34.

Fullagar S (2017) Post-qualitative inquiry and the new materialist turn: Implications for sport, health and physical culture research. Qualitative Research in Sport, Exercise and Health 9(2): 247-257.

Furness Z (2010). One Less Car: Bicycling and the Politics of Automobility. Philadelphia: Temple University Press.

Harding S (2008) Sciences From Below: Feminisms, Postcolonialisms, and Modernities. Durham: Duke University Press.

Hartmann D and Kwauk C (2011) Sport and development: An overview, critique, and reconstruction. Journal of sport and social issues, 35(3): 284-305.

Harvey J, Horne J and Safai, P (2009) Alterglobalization, global social movements, and the possibility of political transformation through sport. Sociology of Sport Journal, 26(3): 383-403. 
Latour B (1988) The politics of explanation: An alternative. In: S Woolgar (ed), Knowledge and Reflexivity: New Frontiers in the Sociology of Knowledge. London: Sage, pp. 155-176.

Latour B (1999) Pandora's Hope: Essays on the Reality of Science Studies. Cambridge: Harvard University Press.

Latour B (2005) Reassembling the Social: An Introduction to Actor-Network-Theory. Oxford: Oxford University Press.

Law J (1992) Notes on the theory of the actor-network: Ordering, strategy, and heterogeneity. Systems Practice 5(4): 379-393.

Levermore R (2009) Sport-in-international development: Theoretical frameworks. In: R Levermore and A Beacom (eds) Sport and International Development. Basingstoke: Palgrave Macmillan, pp. 26-54.

Levermore R (2011) Evaluating sport-for-development: Approaches and critical issues. Progress in Development Studies 11(4): 339-353.

Lindsey I and Grattan A (2012) An 'international movement'? Decentring sport-for-development within Zambian communities. International Journal of Sport Policy and Politics 4(1): 91110.

Markula P (In Press) What is new about new materialism for sport sociology? Reflections on body, movement, and culture. Sociology of Sport Journal.

Pojani D and Stead D (2015) Sustainable urban transport in the developing world: beyond megacities. Sustainability 7(6): 7784-7805.

Schulenkorf N, Sherry E and Rowe K (2016) Sport for development: An integrated literature review. Journal of Sport Management 30(1): 22-39. 
Sharon T (2013) Human Nature in an Age of Biotechnology: The Case for Mediated Posthumanism (Vol. 14). New York: Springer Science \& Business Media.

Sterchele D (2015) De-sportizing physical activity: From sport-for-development to play-fordevelopment. European Journal for Sport and Society 12(1): 97-120.

Stoddart MCJ (2012) Making Meaning Out of Mountains: The Political Ecology of Skiing. Vancouver: UBC Press.

Svensson PG and Woods H (2017) A systematic overview of sport for development and peace organisations. Journal of Sport for Development 5(9): 36-48.

Tsing AL (2005) Friction: An Ethnography of Global Connection. Princeton: Princeton University Press.

UN Environment (2018) "When it rains, my heart sinks": Climate change takes a toll in Uganda. Retrieved 10 September 2019 from https:/www.unenvironment.org/news-andstories/story/when-it-rains-my-heart-sinks-climate-change-takes-toll-uganda.

United Nations (n.d.) World Bicycle Day. Retrieved 10 September 2019 from https://www.un.org/en/events/bicycleday/.

United Nations (2004) Universal language of sport brings people together, teaches teamwork, tolerance, Secretary-General says at launch of international year. Retrieved 10 September 2019 from https://www.un.org/press/en/2004/sgsm9579.doc.htm.

Village Bicycle Project (2016) Home. Retrieved 4 November 2019 from https://www.villagebicycleproject.org/.

Watson MC (2011) Cosmopolitics and the subaltern: Problematizing Latour's idea of the commons. Theory, Culture \& Society 28(3): 55-79. 
Webb A and Richelieu A (2016) Sport for development and peace in action: Building facts for funding. Journal of Sport and Social Issues 40(5): 432-456.

Weedon G (2015) Camaraderie reincorporated: Tough Mudder and the extended distribution of the social. Journal of Sport and Social Issues 39(6): 431-454.

World Bicycle Relief (2019). The Bike. Retrieved 10 September 2019 from https://worldbicyclerelief.org/en/bike/.

World Bicycle Relief (2016). Why Buffalo? Retrieved 10 September 2019 from http://www.buffalobicycle.com/why-buffalo.

Yang YK and Wu SL (2015) An exploratory study to understand the internationalization strategies of social enterprises. Journal of Social Entrepreneurship 6(1): 31-41.

Table 1 - Study participants' organizations $(n=19)$

\begin{tabular}{|l|l|}
\hline \multicolumn{1}{|c|}{ NGO Name } & \multicolumn{1}{c|}{ Organizational aims/activities } \\
\hline 88Bikes & $\begin{array}{l}\text { Receives financial donations to purchase bicycles from local vendors } \\
\text { in contexts around the world; in turn donates bicycles, especially to } \\
\text { survivors of human trafficking. }\end{array}$ \\
\hline $\begin{array}{l}\text { Amuru Village Health } \\
\text { Team }\end{array}$ & $\begin{array}{l}\text { Based in Uganda. Bicycles used as part of a mission to achieve } \\
\text { sustainable public health. }\end{array}$ \\
\hline $\begin{array}{l}\text { Bicycles Against } \\
\text { Poverty (BAP) }\end{array}$ & $\begin{array}{l}\text { Based in Uganda. Distribute bicycles to rural communities to } \\
\text { improve the standard of living, with a focus on agricultural } \\
\text { sustainability. }\end{array}$ \\
\hline $\begin{array}{l}\text { Bicycling } \\
\text { Empowerment } \\
\text { Network (BEN) }\end{array}$ & $\begin{array}{l}\text { Based in South Africa. Provides access to opportunities through } \\
\text { cycling; aims to create a cycling culture. }\end{array}$ \\
\hline Bikes 4 Life & $\begin{array}{l}\text { Collects, restores, and donates bicycles in marginalized and } \\
\text { impoverished communities around the world. Views cycling as a } \\
\text { means of empowerment and independence. }\end{array}$ \\
\hline $\begin{array}{l}\text { Bikes Without Borders } \\
\text { (BWB) }\end{array}$ & $\begin{array}{l}\text { Uses bikes to increase access to health, economic, and educational } \\
\text { opportunities and resources in marginalized communities. }\end{array}$ \\
\hline $\begin{array}{l}\text { Charlie's FreeWheels } \\
\text { Uses bicycles to empower youth and encourage personal } \\
\text { development, as well as motivate social change within local } \\
\text { communities. }\end{array}$ \\
\hline $\begin{array}{l}\text { First African Bicycle } \\
\text { Information } \\
\text { Organization (FABIO) }\end{array}$ & $\begin{array}{l}\text { Based in Uganda. Promotes access to social and economic services } \\
\text { through bicycle advocacy and empowerment. }\end{array}$ \\
\hline
\end{tabular}




\begin{tabular}{|l|l|}
\hline HOE Consulting & $\begin{array}{l}\text { Provides consultation for cycling and mobility projects, including } \\
\text { infrastructure and cycling advocacy. }\end{array}$ \\
\hline Hope 4 Humans & $\begin{array}{l}\text { Based in Uganda. Uses bicycles to provide medical and social } \\
\text { support services to families and communities affected by Nodding } \\
\text { Syndrome. }\end{array}$ \\
\hline $\begin{array}{l}\text { Kadama Widows } \\
\text { Association }\end{array}$ & $\begin{array}{l}\text { Based in Uganda. Provides support to people and families } \\
\text { affected by HIV/AIDS. }\end{array}$ \\
\hline Kara-Tunga & $\begin{array}{l}\text { Based in Uganda. Offers bicycle tours as a means to explore the } \\
\text { Eastern region of Karamoja. }\end{array}$ \\
\hline Mityana Open Troops & $\begin{array}{l}\text { Aims to empower and improve the standard of living for } \\
\text { marginalized groups, including people with disabilities, vulnerable } \\
\text { youth, and orphans through education. }\end{array}$ \\
\hline $\begin{array}{l}\text { Pedals 4 Progress } \\
\text { (P4P) }\end{array}$ & $\begin{array}{l}\text { Encourages sustainable economic development by recycling bicycles } \\
\text { from the U.S. and shipping them to communities around the world. }\end{array}$ \\
\hline Union of Hope (UOH) & $\begin{array}{l}\text { Based in Uganda. A community-based women's NGO; uses bicycles } \\
\text { for mobility, accessing resources, and other social and economic } \\
\text { factors. }\end{array}$ \\
\hline $\begin{array}{l}\text { Village Bicycle Project } \\
\text { (VBP) }\end{array}$ & $\begin{array}{l}\text { Offers bicycles to individuals and groups in Ghana and Sierra Leone } \\
\text { to increase access to affordable and sustainable transportation. }\end{array}$ \\
\hline $\begin{array}{l}\text { World Bicycle Relief } \\
\text { (WBR) }\end{array}$ & $\begin{array}{l}\text { Uses the 'power of bicycles' to mobilize people in order to } \\
\text { achieve independence and offer transportation means. }\end{array}$ \\
\hline India Bikes* & $\begin{array}{l}\text { Based in India. Seeks to empower women living in rural areas } \\
\text { through bicycle provision. }\end{array}$ \\
\hline $\begin{array}{l}\text { Bicycles for the } \\
\text { World* }\end{array}$ & $\begin{array}{l}\text { Ships donated bicycles from around the world to provide mobility to } \\
\text { individuals and communities while creating employment. }\end{array}$ \\
\hline
\end{tabular}

*Pseudonym 